\title{
Inflammatory cast of the tympanic membrane after acute otitis media
}

\author{
J BYUN $^{1}$, DS MASSI ${ }^{2}$, A SEHGAL ${ }^{3}$, M SAADIA-REDLEAF $^{3}$ \\ ${ }^{1}$ College of Medicine and ${ }^{2}$ Department of Pathology, University of Illinois, and ${ }^{3}$ Illinois Eye and Ear Infirmary, \\ Chicago, Illinois, USA
}

\begin{abstract}
Objective: To describe a relatively unknown clinical entity - inflammatory cast of the tympanic membrane after acute otitis media - and its simple out-patient treatment.

Study design: Retrospective review of case series.

Setting: Subspecialty practice at a tertiary hospital.

Patients: Seven patients diagnosed previously with acute otitis media with perforation or otitis externa, and with persistent ear discomfort.

Methods: Retrospective chart review.

Results: The patients presented with weeks to months of persistent hearing loss after acute otitis media with perforation or acute otitis externa. Visits to their primary care physicians had been uninformative. After comparison of the affected and unaffected tympanic membranes, a thin, hard cast was identified and removed from the affected tympanic membrane. Improvement in hearing was documented in the three patients who underwent audiometric testing; the remainder had subjective improvement without audiometric evaluation.

Conclusion: Otolaryngologists should be aware of the possibility of an inflammatory cast of the tympanic membrane following acute otitis media with perforation or otitis externa, and should carefully compare the unaffected and affected ears in such cases. Treatment - removal of the rigid cast - is both simple and effective.
\end{abstract}

Key words: Otitis Media; Hearing Loss, Conductive; Pathology; External Auditory Canal; Keratins

\section{Introduction}

Patients often present with external auditory canal obstruction caused by products of the canal micro-environment: cerumen, keratosis obturans and cholesteatoma. ${ }^{1}$ Disturbances of cerumen accumulation are related to the well documented epithelial migration of the skin of the tympanic membrane and external auditory canal. ${ }^{2}$ In cases of keratosis obturans, histological examination reveals tightly packed keratinaceous lamellae without cell bodies. ${ }^{3}$ While keratosis obturans circumferentially envelopes the entire external auditory canal, external auditory canal cholesteatoma is a focal disorder with subadjacent osteonecrosis and focal epithelial loss. ${ }^{1}$ Also, while keratosis obturans typically forms a plug-like cast which fills the entire canal, the products of cholesteatoma are not always completely obstructive.

We report here a new clinical entity distinct from any previously described. We present a patient series, with illustrations, of a cast of the tympanic membrane composed of inflammatory products, presenting after acute otitis media or otitis externa. The distinguishing features of this cast are: formation after acute otitis media with perforation or otitis externa; a painless, 'plugged' sensation with or without audiometric evidence of hearing loss; and appearance of a thin, hard layer which resembles normal morphology and which coats the tympanic membrane and external canal. These patients often present after previous, frustrating visits to other medical providers. The uninformed physician may easily overlook their problem, while the informed one easily resolves it.

\section{Case series}

This study was approved by our Institutional Review Board.

Table I outlines the clinical details for seven patients with a typical inflammatory cast, both male and female adults, aged between 29 and 73 years. All patients reported an initial painful otitis media with perforation or otitis externa, which resolved with antibiotics but which left them with continued discomfort from a plugged sensation. Typically, patients had seen two to three doctors before the correct diagnosis was made. The key to successful diagnosis was the otolaryngologist's awareness of the possibility of an inflammatory cast, together with rigorous comparisons with the contralateral tympanic membrane and external auditory canal. Those patients who underwent audiometric testing pre- and post-cleaning demonstrated improved pure tone thresholds; patients who did not undergo testing reported subjective hearing improvement.

The most seriously affected patient was a 36-year-old woman who had seen 3 doctors in 24 weeks since suffering acute otitis media with perforation. She presented with 
TABLE I

INFLAMMATORY CAST OF TYMPANIC MEMBRANE AFTER ACUTE OTITIS: PATIENT DATA

\begin{tabular}{|c|c|c|c|c|c|c|c|}
\hline \multirow{2}{*}{$\begin{array}{l}\text { Pt age (y) } \\
\& \operatorname{sex}\end{array}$} & \multicolumn{2}{|c|}{ Initial presentation } & \multicolumn{5}{|c|}{ Final presentation } \\
\hline & Symptoms & Diagnosis & $\begin{array}{c}\text { Weeks } \\
\text { preceding }\end{array}$ & Symptoms & $\begin{array}{l}\text { Drs prev } \\
\text { seen }\end{array}$ & Contralat TM & Hearing change* \\
\hline $29 \mathrm{~F}$ & $\begin{array}{l}\text { Extreme } \mathrm{R} \text { ear pain with } \\
\text { perforation }\end{array}$ & $\begin{array}{l}\mathrm{R} \text { OM with } \\
\text { perforation }\end{array}$ & 3 & $\begin{array}{l}\mathrm{R} \text { hearing } \\
\text { loss }\end{array}$ & 3 & Normal & $\begin{array}{l}\text { Subjective } \\
\text { improvement }\end{array}$ \\
\hline $36 \mathrm{~F}$ & $\begin{array}{l}\text { Extreme L ear pain with } \\
\text { perforation }\end{array}$ & $\begin{array}{l}\text { L OM with } \\
\text { perforation }\end{array}$ & 24 & $\begin{array}{l}\mathrm{L} \text { hearing } \\
\text { loss }\end{array}$ & 3 & Normal & $\begin{array}{l}40 \mathrm{~dB} \\
\text { improvement }\end{array}$ \\
\hline $38 \mathrm{~F}$ & Ear pain \& infection & Bilat $\mathrm{OE}$ & 18 & $\begin{array}{l}\text { Bilat hearing } \\
\text { loss }\end{array}$ & 2 & $\underset{\text { cast }^{\dagger}}{\text { Inflammatory }}$ & $\begin{array}{l}\text { Subjective } \\
\text { improvement }\end{array}$ \\
\hline $59 \mathrm{~F}$ & Sudden $\mathrm{L}$ hearing loss & $\mathrm{L} \mathrm{OE}$ & 2 & $\begin{array}{l}\mathrm{L} \text { hearing } \\
\text { loss }\end{array}$ & 2 & Normal & $\begin{array}{l}\text { Subjective } \\
\text { improvement }\end{array}$ \\
\hline $66 \mathrm{~F}$ & $\begin{array}{l}\mathrm{R} \text { temporal pain } \\
\text { radiating to parietal } \\
\text { scalp }\end{array}$ & R OE & 4 & $\begin{array}{l}\mathrm{R} \text { hearing } \\
\text { loss }\end{array}$ & 5 & Normal & $\begin{array}{l}\text { Unavailable } \\
\text { during review }\end{array}$ \\
\hline $68 \mathrm{M}$ & Sudden $\mathrm{R}$ hearing loss & $\mathrm{R} \mathrm{OE}$ & 6 & $\begin{array}{l}\mathrm{R} \text { hearing } \\
\text { loss }\end{array}$ & 2 & Normal & $\begin{array}{l}10 \mathrm{~dB} \\
\text { improvement }\end{array}$ \\
\hline $73 \mathrm{~F}$ & $\mathrm{~L}$ ear pain & $\mathrm{L} \mathrm{OE}$ & 6 & $\begin{array}{l}\mathrm{L} \text { hearing } \\
\text { loss }\end{array}$ & 3 & Normal & $\begin{array}{l}15 \mathrm{~dB} \\
\text { improvement }\end{array}$ \\
\hline
\end{tabular}

${ }^{*}$ Following cast removal. ${ }^{\dagger}$ Casts present bilaterally. $\mathrm{Pt}=$ Patient; $\mathrm{y}=$ years; Drs prev seen $=$ doctors previously seen; contralat $\mathrm{TM}=$ contralateral tympanic membrane; $\mathrm{F}=$ female; $\mathrm{R}=$ right; $\mathrm{OM}=$ otitis media; $\mathrm{L}=$ left; bilat = bilaterally; $\mathrm{OE}=$ otitis externa; $\mathrm{M}=$ male

hearing loss and ear discomfort, seeking a second opinion, 3 days before a scheduled ossiculoplasty. Figure 1 shows this patient's pre-operative temporal bone computed tomography, and illustrates the inflammatory cast on the external surface

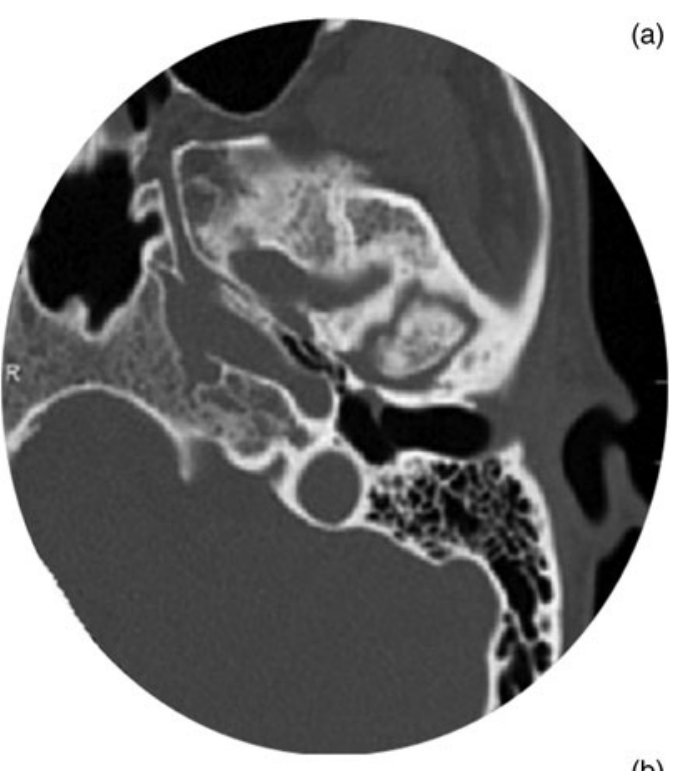

(a)

(b)

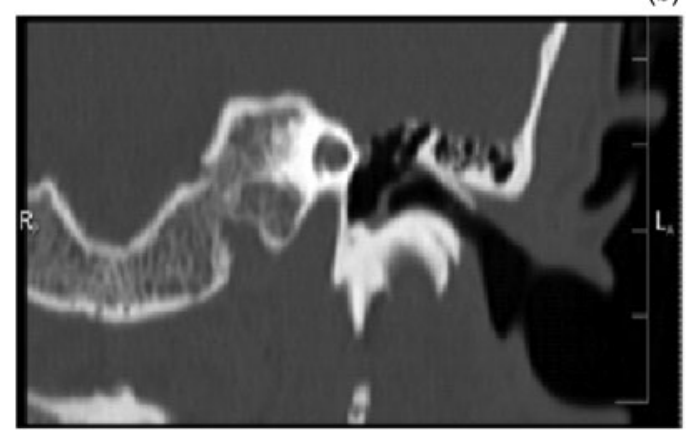

FIG. 1

(a) Axial and (b) coronal computed tomography images of the temporal bone of a 36-year-old woman originally scheduled for ossiculoplasty, prior to correct diagnosis. of the tympanic membrane. Removal of this cast resolved the patient's $40 \mathrm{~dB}$ conductive hearing loss.

Figure 2 shows a typical inflammatory cast of the tympanic membrane, identified in another patient after weeks of drops and antibiotics. Figure 3 shows the tympanic membrane midway through cast removal. Figure 4 illustrates the cleaned tympanic membrane, with cast fragments remaining on the external auditory canal skin. Figure 5 shows the inflammatory cast with a notch indicating the position of the malleus.

The photomicrograph reproduced as Figure 6 shows a largely acellular, rigid eschar with embedded neutrophils and lymphocytes. Loose orthokeratin is present on the surface. Despite the inflammatory cast's gross appearance, reminiscent of sloughed skin, it is composed largely of an acellular exudate with sparse embedded inflammatory cells.

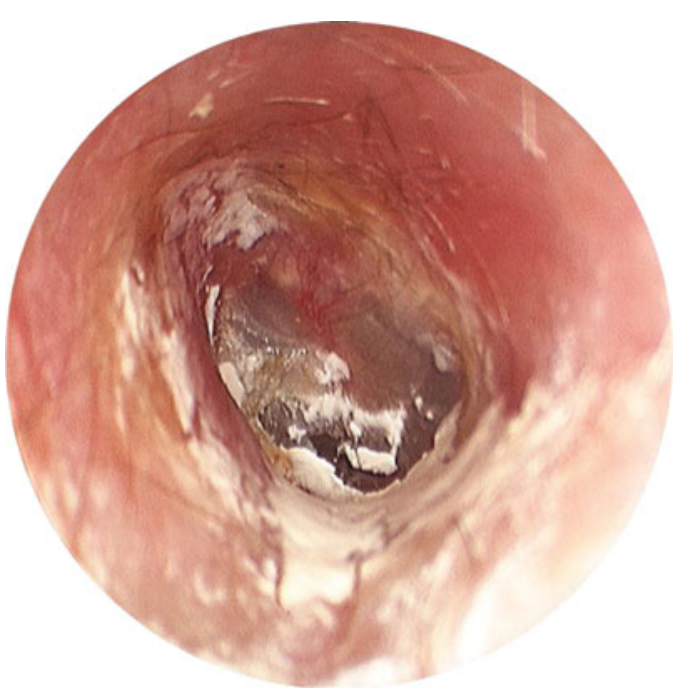

FIG. 2

Procedural microscope view of the left tympanic membrane of a 73 year-old woman, 24 weeks after acute otitis media and externa, showing limited exfoliation of inflammatory cast lamella at 6 o'clock. 


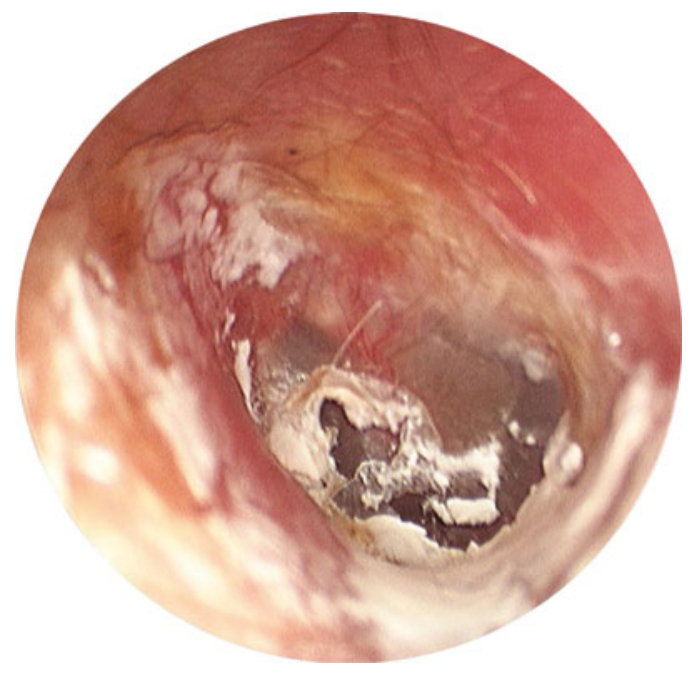

FIG. 3

Procedural microscope view of the same patient shown in Figure 2, midway through cast removal.

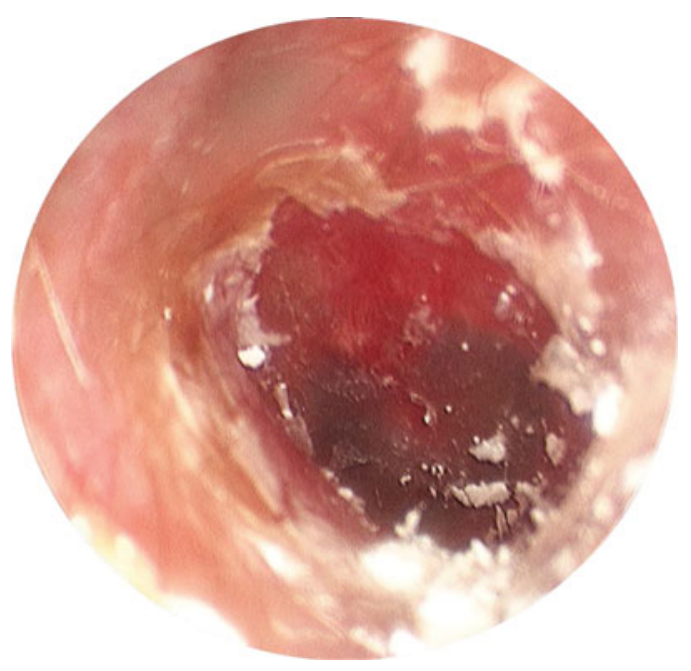

FIG. 4

Procedural microscope view of the same patient shown in Figure 2 , showing the normal tympanic membrane revealed after removal of the thin, hard cast, fragments of which remain on the external auditory canal skin.

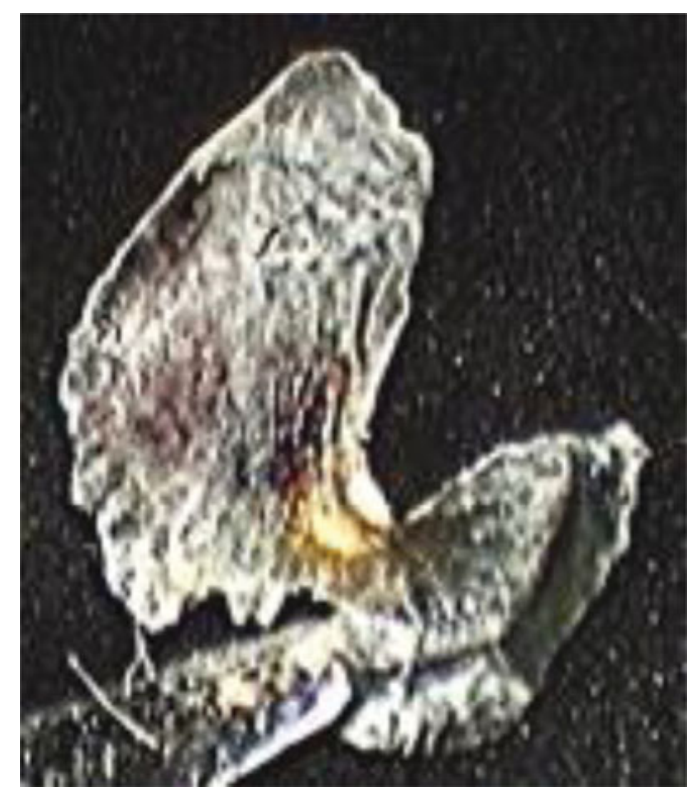

FIG. 5

The inflammatory cast removed from the patient shown in Figure 2, showing a notch indicating the position of the malleus.

\section{Discussion}

The presented cases all involved a previous episode of acute otitis media with perforation or otitis externa, which successfully resolved but left the patient with a hearing deficit. Each patient's hearing loss improved dramatically after careful visual examination under procedural microscopy and subsequent removal of an inflammatory cast on the tympanic membrane.

- Acute otitis media with perforation and acute otitis externa often lead to hearing loss after resolution

- Careful comparison with the contralateral tympanic membrane may reveal an inflammatory cast covering the affected tympanic membrane

- Removal of this cast may dramatically improve hearing

This cast matched the size and shape of the tympanic membrane, suggesting a possible mechanism for its development.

(a)
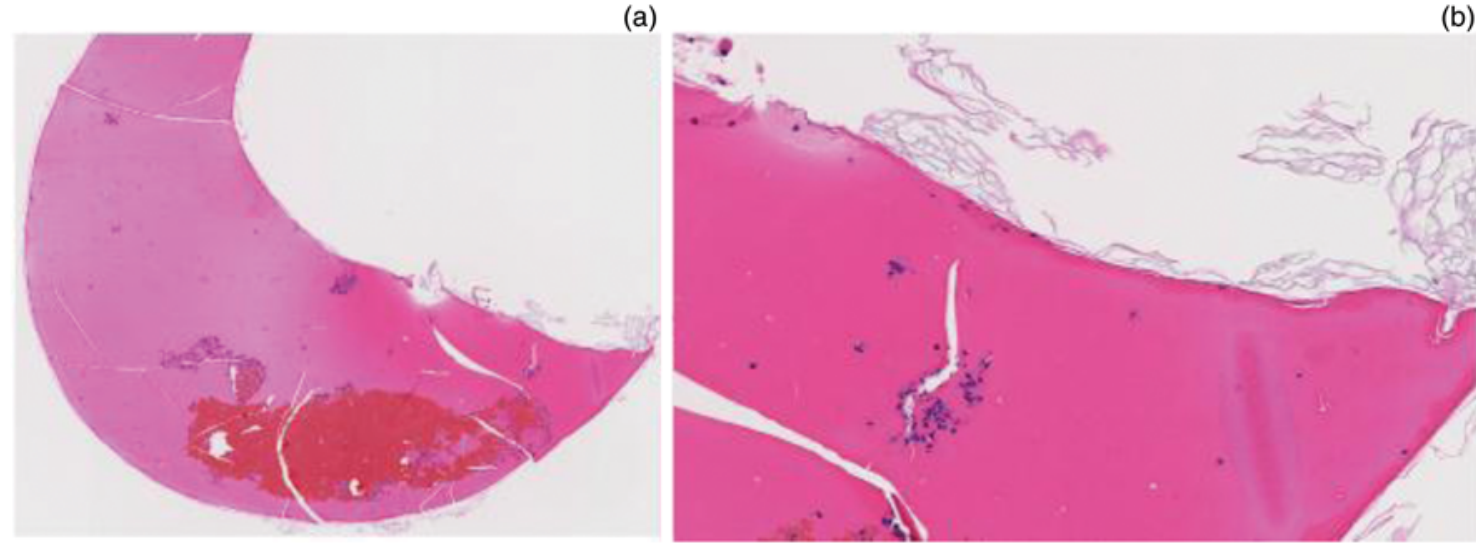

FIG. 6

Photomicrographs of a tympanic membrane inflammatory cast at (a) $\times 40$ and (b) $\times 200$ magnification, showing a largely acellular, proteinaceous eschar with scattered lymphocytes and neutrophils. (H\&E) 
Specifically, we hypothesise that a serous exudate with inflammatory cells coats the tympanic membrane and the external canal skin. This hardens to form a fibro-exudative cast which is uncomfortable and which also impedes tympanic membrane vibration.

The key features enabling identification of this inflammatory cast of the tympanic membrane are: a normal contralateral ear, a high index of clinical suspicion for the problem, and resolution of hearing loss upon meticulous cleaning of the tympanic membrane.

\section{Acknowledgement}

We would like to thank Dr Todd Berinstein for his help in the recognition of this clinical entity.

\section{References}

1 Persaud RA, Hajioff D, Thevasagayam MS, Wareing MJ, Wright A. Keratosis obturans and external ear canal cholesteatoma: how and why we should distinguish between these conditions. Clin Otolaryngol Allied Sci 2004;29:577-81

2 Revadi G, Prepageran N, Raman R, Sharizal TA. Epithelial migration on the external ear canal wall in normal and pathologic ears. Otol Neurotol 2011;32:504-7

3 Dalton SR, Ferringer T, Mowad CM. Obstruction of the external auditory canal by a keratin cast: keratosis obturans or cholesteatoma? J Am Acad Dermatol 2011;65:88-9

Address for correspondence:

Dr Saadia-Redleaf,

University of Illinois department of pathology,

1853 W Polk St (MC 785),

Chicago, IL 60612, USA

Fax: +1 3129964910

E-mail: mredleaf@uic.edu

Dr M Saadia-Redleaf takes responsibility for the integrity of the content of the paper

Competing interests: None declared 